\title{
Expression of EGFR and follicular dendritic markers in lymphoid follicles from patients with Castleman's disease
}

\author{
JUHIE LEE ${ }^{1}$, JU YEON BAN ${ }^{2}$, KYU YEOUN WON ${ }^{1}$, GYO-YONG KIM $^{1}$, SUNG-JIG LIM ${ }^{1}$, SUN LEE ${ }^{1}$, \\ YOUN WHA KIM ${ }^{1}$, YONG-KOO PARK ${ }^{1}$ and SANG SOOK LEE ${ }^{3}$ \\ ${ }^{1}$ Department of Pathology, Kyung Hee University Medical Center, Seoul 130-702; ${ }^{2}$ Kohwang Medical Research Institute, \\ College of Medicine, Kyung Hee University, Seoul 130-701; ${ }^{3}$ Department of Pathology, \\ College of Medicine, Keimyung University, Daegu 704-701, Korea
}

Received May 27, 2008; Accepted July 14, 2008

DOI: 10.3892/or_00000082

\begin{abstract}
This study investigated the useful morphologic and immunophenotypic findings for the diagnosis of Castleman's disease (CD). We focused on the distribution and expression of follicular dendritic cells (FDC) in lymphoid follicles from patients with $\mathrm{CD}$. Eleven $\mathrm{CD}$ cases of the hyaline vascular (HV) variant and six cases of the plasma cell (PC) variant were studied using tissue microarray and paraffin resistant monoclonal antibodies CD21, CD35, and EGFR, a new novel marker of FDC, as well as an antibody against human herpes virus 8 (HHV8). Epstein-Barr virus (EBV) was detected by means of in situ hybridization with a fluorescein isothiocyanate-labeled EBV-encoded RNA (EBER) specific oligonucleotide. The FDC network of the PC variant $(n=4)$ was similar to that seen in normal or reactive germinal centers. In contrast, all HV variants and 2 cases of the PC variant were either expanded, disrupted, or exhibited multiple tight collections of FDC both in germinal centers and in mantle zone lymphocytes. The expanded mantle zone lymphocytes were $\mathrm{CD} 20^{+}, \mathrm{Bcl}^{+}, \mathrm{PAX}^{+}$, and MUM1- with less number of $\mathrm{CD}^{+} \mathrm{T}$ cells admixed. Other features of the $\mathrm{HV}$ variant included follicular regression and vascular ingrowth of the germinal centers, whereas features of the PC variant were follicular hyperplasia and interfollicular plasmacytosis. In addition, EBV infection was positive in three CD cases, and one case had co-expression of HHV8 and EBV infection. Taken together, we found immunophenotypic differences of mantle zone lymphocytes and FDC network patterns of lymphoid follicles in CD. Thus, we conclude that these differences are relevant for the differential diagnosis of the two histopathologic variants of CD.
\end{abstract}

Correspondence to: Dr Juhie Lee, Department of Pathology, Kyung Hee University Medical Center, Seoul 130-702, Korea

E-mail: leejuhie@khmc.or.kr

Key words: Castleman's disease, follicular dendritic cells, epidermal growth factor receptor, hyaline vascular variant, plasma cell variant, immunohistochemistry, tissue microarray

\section{Introduction}

Castleman's disease (CD) is a rare disorder of unknown etiology that is characterized by masses of lymphoid tissue. $\mathrm{CD}$ is classified into two histological subtypes; the hyaline vascular (HV) variant and the plasma cell (PC) variant. HV is more common and is usually associated with unicentric clinical entity with a much better prognosis than the PC variant, which is multicentric clinical entity associated with a worse prognosis (1). The distinction between the HV and $\mathrm{PC}$ variants is of high clinical interest, since this distinction implies different treatment.

Different etiopathogenesis of CD subtypes has been suggested. Human herpes virus 8 (HHV8) infections are highly associated with multicentric CD (MCD). These patients have an increased risk of HHV8 associated neoplasm, including Kaposi's sarcoma and extranodal B cell lymphoma $(2,3)$. Overproduction of the cytokine interleukin 6 (IL-6) is partially explained to drive plasma cell proliferation (4). However, the pathogenesis of hyaline vascular Castleman's disease (HVCD) is less clearly understood. A recent cytogenetic study showed a clonal karyotypic abnormality of stromal cells in HVCD (5). Furthermore, HVCD has been proposed to be a disease of follicular dendritic cells (FDC). The immunohistochemical study of FDC marker, mainly the CD21 in CD has already been reported by several authors (6-9). Here, two conventional markers of FDC, CD21 and CD35 and a new novel antibody, epidermal growth factor receptor (EGFR) were chosen for this study because a single marker was not enough to recognize the specific or related cells especially in paraffin embedded tissue sections. Recently EGFR expression in FDCs has been reported in CD and FDC sarcoma (10).

Although the histological diagnosis of CD is straightforward, it can be difficult or impossible to diagnose CD with certainty in some cases of unusual location or cases of histological variants. We questioned which findings are the most important for the diagnosis or what are the minimum requirements for a diagnosis of $\mathrm{CD}$, especially with a small needle biopsy specimen. In our present study, we analyzed the morphologic and immunohistochemical findings of 17 cases of $\mathrm{CD}$ with an emphasis on the presence of FDC expression pattern. 
Table I. The characteristics of patients with Castleman's disease.

\begin{tabular}{|c|c|c|c|c|c|c|c|}
\hline Case & Gender & $\begin{array}{c}\text { Age } \\
\text { (years) }\end{array}$ & Site & $\begin{array}{l}\text { Size } \\
(\mathrm{cm})\end{array}$ & $\begin{array}{l}\text { Histological } \\
\text { type }\end{array}$ & Involvement & Clinical symptoms \\
\hline 1 & $\mathrm{~F}$ & 46 & Retroperitoneum & $7 \times 6 \times 5$ & $\mathrm{HV}$ & Single & No \\
\hline 2 & $\mathrm{~F}$ & 43 & Neck & $3 \times 2 \times 1.5$ & $\mathrm{HV}$ & Single & No \\
\hline 3 & $\mathrm{~F}$ & 40 & Mediastinum, anterior & $9 \times 4 \times 2$ & $\mathrm{HV}$ & Single & No \\
\hline 4 & $\mathrm{~F}$ & 14 & Neck, left & $5 \times 3 \times 2$ & $\mathrm{HV}$ & Single & No \\
\hline 5 & M & 38 & Retroperitoneum & $6 \times 6 \times 4$ & $\mathrm{HV}$ & Single & $\begin{array}{l}\text { Anemia and hypoalbuminemia } \\
\text { hypoalbuminemia }\end{array}$ \\
\hline 6 & $\mathrm{~F}$ & 49 & Neck, right & $5.6 \times 4.7 \times 2.5$ & $\mathrm{HV}$ & Single & Anemia \\
\hline 7 & $\mathrm{~F}$ & 28 & Axilla, right & $4 \times 2.7$ & $\mathrm{HV}$ & Single & No \\
\hline 8 & $\mathrm{~F}$ & 30 & Chest wall, left & $7.5 \times 4.5 \times 3$ & HV & Single & Anemia \\
\hline 9 & $\mathrm{~F}$ & 14 & Neck, right & $1.5 \times 1 \times 0.7$ & $\mathrm{HV}$ & Multiple & No \\
\hline 10 & M & 36 & Neck & $3.5 \times 3 \times 2$ & $\mathrm{HV}$ & Single & No \\
\hline 11 & $\mathrm{~F}$ & 43 & Mediastinum, anterior & $6 \times 6 \times 5$ & $\mathrm{HV}^{\mathrm{b}}$ & Single & No \\
\hline 12 & M & 57 & Neck & $1 \times 1 \times 0.5$ & $\mathrm{PC}$ & Multiple & $\begin{array}{l}\text { Anemia, thrombocytopenia, } \\
\text { hyperglobulinemia, Kaposi's } \\
\text { sarcoma }^{a}\end{array}$ \\
\hline 13 & M & 67 & Neck & $2.5 \times 2 \times 1.5$ & $\mathrm{PC}$ & Multiple & No \\
\hline 14 & M & 60 & Inguinal & $4 \times 1.5$ & $\mathrm{PC}$ & Multiple & $\begin{array}{l}\text { Anemia and thrombocytopenia, } \\
\text { hypoalbuminemia }\end{array}$ \\
\hline 15 & M & 53 & Axilla, right & $6.5 \times 7 \times 3.5$ & $\mathrm{PC}$ & Multiple & No \\
\hline 16 & $\mathrm{M}$ & 46 & Pelvis, left & $3 \times 2.2 \times 1.5$ & $\mathrm{PC}$ & Single & Eosinophilia \\
\hline 17 & $\mathrm{M}$ & 47 & Axilla, left & $4 \times 3$ & $\mathrm{PC}^{\mathrm{c}}$ & Multiple & Splenomegaly, B-symptoms \\
\hline
\end{tabular}

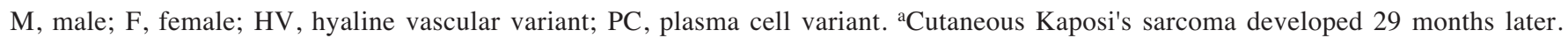
${ }^{\mathrm{b}}$ Follicular dendritic cell tumor arising in Castleman's disease. ${ }^{\mathrm{c} P l a s m a b l a s t i c ~ l y m p h o m a ~ a r i s i n g ~ i n ~ m u l t i c e n t r i c ~ C a s t l e m a n ' s ~ d i s e a s e . ~}$

\section{Materials and methods}

Specimen. We analyzed hematoxylin and eosin (H\&E) stained tissue sections from 17 patients with $\mathrm{CD}$ that were collected from two institutes, Kyung Hee University Medical Center and Keimyung University School of Medicine, during the period between 1998 and 2005. Slides were evaluated to assess the degree of follicular hyperplasia, follicular regression, dysplastic follicles, mantle cell proliferation, vessels in germinal centers and interfollicular areas, plasma cell proliferation, and cellular atypia with sclerosis. One case that was complicated by follicular dendritic cell tumors and one case with plasmablastic lymphoma were grouped as HV and PC types, respectively. The patient records from two hospitals were reviewed retrospectively. Personal demographic data, medical history, familial history, and CD characteristics were analyzed. We classified patients as having localized CD if they presented with only one group of lymph nodes histologically involved in $\mathrm{CD}$ and as having MCD if they presented with involvement of two or more lymph node groups. Systemic symptoms were attributed to CD if no other cause was found.

Tissue microarray construction. Twenty-three representative paraffin blocks were retrieved from a total of 17 patients. At least three or four representative $6 \mathrm{~mm}$ cores of tissue were taken from each paraffin donor block and arrayed into the recipient wax block to create tissue microarray. One section from each microarray was stained with H\&E to confirm the histopathological diagnosis and sampling adequacy.

Immunohistochemistry and Epstein-Barr virus (EBV)-encoded RNA (EBER) in situ hybridization. An immunohistochemical study was carried out on the tissue microarray using a Bond$\mathrm{maX}$ autoimmunostainer (Vision Biosystems, Australia). Briefly, sections of the tissue microarray were dewaxed, rehydrated, and an antigen retrieval step was performed. A panel of antibodies directed against T-cell marker CD3 (PC3/188A, Dako), B-cell markers CD20 (L26, Dako), MUM-1 (MUM1p, Dako), PAX5 (1EW, Novocastra Laboratories), and Bcl2 (AM287-5M, BioGenex Laboratories), FDC markers CD21 (2G9, Novocastra Laboratories), CD35 (RLB25, Novocastra Laboratories), and EGFR(31G7, Zymed Laboratories, Carlsbad, CA), kappa (A8B5, Dako) and lambda light chains (N10/2, Dako), Ki-67 (MIB-1, Dako), and HHV8 LANA (13B10, Novocastra Laboratories) was used. EBV was detected by means of in situ hybridization with fluorescein isothiocyanate-labeled EBER specific oligonucleotide (EBER ISH, Dako), according to the manufacturer's 
Table II. Morphological characteristics of patients with Castleman's disease.

\begin{tabular}{lcc}
\hline & $\begin{array}{c}\mathrm{HV} \\
(\mathrm{n}=11)\end{array}$ & $\begin{array}{c}\mathrm{PC} \\
(\mathrm{n}=6)\end{array}$ \\
\hline Follicular hyperplasia & 1 & 4 \\
Follicular regression & 11 & 3 \\
Dysplastic follicle & 9 & 2 \\
Mantle cell proliferation & 11 & 2 \\
Vessel in germinal center & 9 & 1 \\
Interfollicular vascular proliferation & 11 & 6 \\
Interfollicular plasma cell proliferation & 1 & 6 \\
Cellular atypia & 6 & 2 \\
\hline
\end{tabular}

$\mathrm{HV}$, hyaline vascular variant; PC, plasma cell variant; $\mathrm{n}$, number.

instructions. The sections were evaluated using a light microscope and the intensity of the immunostaining from each section was assessed independently by two observers using the scoring system described below. The proportions of positively-stained cells were assessed for further analysis according to the following groups; no cells, $0 ; 1-10 \%$ of cells, +; 11-50\%, ++; and 51-100\%, +++.

Statistical analysis. Statistical analyses including the t-test were performed using SPSS v11.5 for Windows XPt (SPSS
UK, Ltd., Woking, UK). We regarded p-values $<0.05$ to be significant.

\section{Results}

Clinical findings. The clinical characteristics of the patients are summarized in Table I. The study population consisted of eight males and nine females. The mean age was 45 years (range 14-67 years). Among a total of 17 patients, eleven met the criteria for localized CD; seven of these were asymptomatic. Ten patients with localized CD had histological evidence of HVCD and one had evidence of PC. One patient of HVCD had features of the follicular dendritic cell tumor (case 11). The remaining six cases met the criteria for MCD; three of the cases had systemic symptoms including anemia, thrombocytopenia, and hypoalbuminemia. Five patients had histological findings of the PC variant and one had the HV variant. One MCD patient had HHV8 and EBER positive plasmablastic lymphoma (case 17) and another MCD patient developed a cutaneous Kaposi's sarcoma 29 months later (case 12). The most common sites of biopsy at the presentation of disease were the cervical lymph nodes $(n=7)$, axilla $(n=3)$, retroperitoneum $(n=2)$, mediastinum $(n=2)$, inguinal $(n=1)$, chest wall $(n=1)$, and pelvis $(\mathrm{n}=1)$.

Histological findings. The histological features of all cases are summarized in Table II. The common findings in HVCD patients were follicular regression, dysplastic follicles with mantle cell proliferation, and marked interfollicular vascular proliferation (Fig. 1A). Variable degrees of sclerosis were
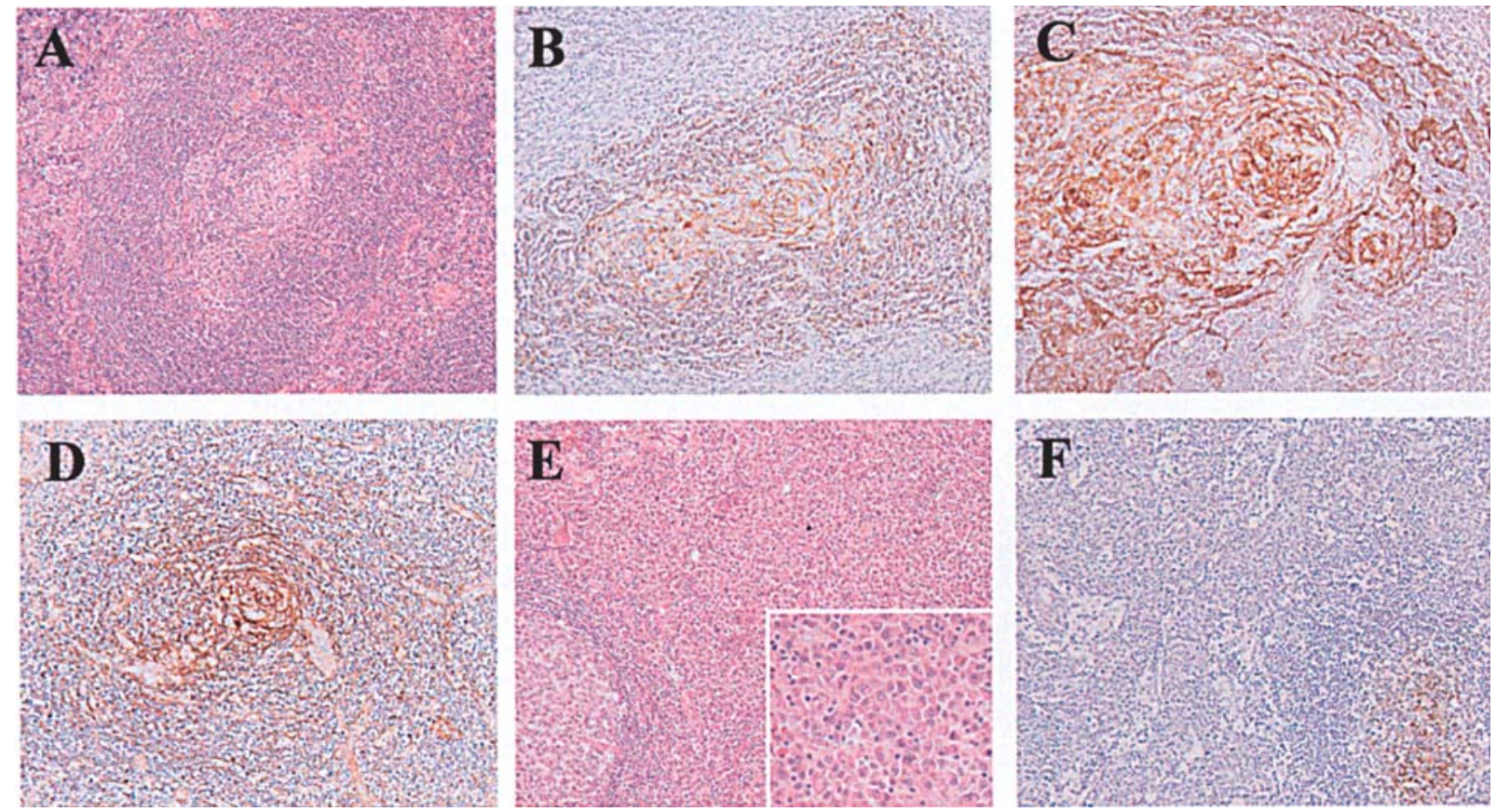

Figure 1. Histology and immunohistochemistry of Castleman's disease. A, Hyaline vascular Castleman's disease; a large lymphoid follicle consisted of concentrically arranged mantle zone lymphocytes surrounding abnormal germinal centers with hyalinized arterioles. Hematoxylin-eosin stain (x200). B, Samples were immunostained with CD21 to delineate the follicular dendritic cells. The expanded network of follicular dendritic cells from regressed follicles extends into the surrounding mantle area (x200). C, High magnification of the CD21 immunostained samples (x200). D, Membranous expression of EGFR in follicular dendritic cells (x200). E, Plasma cell Castleman's disease; diffuse proliferation of plasma cells in the interfollicular region encasing a normal looking lymphoid follicle with a thin layer of mantle zone lymphocytes. High magnification of plasma cells (inset). Hematoxylin-eosin stain (x200). F, CD21 immunostaining revealed central intense staining within the lymphoid follicle (x200). 
Table III. Expression of follicular dendritic cell markers and viral infections in patients with Castleman's disease.

\begin{tabular}{|c|c|c|c|c|c|c|c|}
\hline \multirow[b]{2}{*}{ Case } & \multirow[b]{2}{*}{ Histological type } & \multicolumn{4}{|c|}{ Mantle cells of lymphoid follicles } & \multirow[b]{2}{*}{ EBV } & \multirow[b]{2}{*}{ HHV } \\
\hline & & CD3 & CD21 & CD35 & EGFR & & \\
\hline 1 & $\mathrm{HV}$ & + & +++ & +++ & ++ & - & - \\
\hline 2 & $\mathrm{HV}$ & + & +++ & +++ & +++ & - & - \\
\hline 3 & $\mathrm{HV}$ & + & +++ & +++ & +++ & - & - \\
\hline 4 & $\mathrm{HV}$ & + & +++ & +++ & +++ & - & - \\
\hline 5 & $\mathrm{HV}$ & + & - & +++ & + & - & - \\
\hline 6 & $\mathrm{HV}$ & + & +++ & +++ & ++ & + & - \\
\hline 7 & $\mathrm{HV}$ & + & +++ & +++ & +++ & - & - \\
\hline 8 & $\mathrm{HV}$ & + & +++ & +++ & +++ & - & - \\
\hline 9 & $\mathrm{HV}$ & + & +++ & +++ & +++ & - & - \\
\hline 10 & HV & + & +++ & +++ & +++ & - & - \\
\hline 11 & $\mathrm{HV}^{\mathrm{a}}$ & + & +++ & ++ & ++ & - & - \\
\hline 12 & $\mathrm{PC}$ & NA & NA & NA & NA & - & - \\
\hline 13 & $\mathrm{PC}$ & + & + & +++ & +++ & - & - \\
\hline 14 & $\mathrm{PC}$ & ++ & - & + & ++ & - & - \\
\hline 15 & $\mathrm{PC}$ & ++ & - & + & + & + & - \\
\hline 16 & PC & ++ & + & ++ & + & - & - \\
\hline 17 & $\mathrm{PC}^{\mathrm{b}}$ & ++ & +++ & +++ & +++ & + & + \\
\hline
\end{tabular}

HV, hyaline vascular variant; PC, plasma cell variant; NA, not available; EBV, Epstein-Barr virus; HHV8, human herpes virus 8. ${ }^{\mathrm{a} F o l l i c u l a r}$

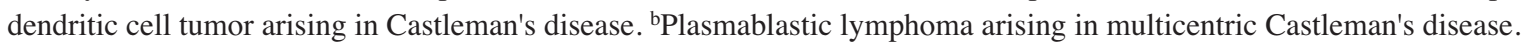

present in six HVCD cases (data not shown). Cellular atypia was present in 6 out of 11 cases of HVCD but those atypical cells were immunohistochemically proven to be follicular dendritic cells. The characteristic findings restricted to PCCD were follicular hyperplasia, marked interfollicular plasma cell proliferation, and blood vessels of varying degrees (Fig. 1E). Marked mantle cell proliferation with regressed germinal centers was found in 2 out of 6 PCCD cases. Sclerosis was found in one case. Two cases of PCCD had cellular atypia either of the plasma cells or of follicular dendritic cells.

Immunohistochemical findings. The immunohistochemical FDC features and viral infection in all cases are summarized in Table III. Strong expression of FDC markers (CD21, CD35, and EGFR) was observed in lymphoid follicles of the $\mathrm{HV}$ variant compared to the $\mathrm{PC}$ variant. A meshwork of the FDC in the germinal centers was highlighted by CD21, CD35, and EGFR expression. We found a significantly distinct difference in the types of FDC networks, as determined by CD21 immunostaining between PC and HV variants $(\mathrm{p}<0.013)$. PCCD had CD21 positively-stained FDC patterns that were similar to the normal germinal centers of the lymphoid follicles (Fig. 1F), whereas abnormal tight concentric network FDC patterns in the germinal centers with expanded mantle zones was found in HVCD (Fig. 1B and C). Similar to CD21, the strongest (+++) EGFR (Fig. 1D) and CD35 expressions were more frequent in the HVCD $(7 / 11$, to $10 / 11)$ than in PCCD $(2 / 6,2 / 6)$ which had regressed abnormal follicles, but its statistical significance was not observed. In addition, the mantle zone lymphocytes of HVCD were exclusively comprised of $\mathrm{B}$ cells that stained with $\mathrm{Bcl} 2^{+}, \mathrm{CD} 20^{+}$, and $\mathrm{PAX}^{+}$, whereas those of PCCD were $\mathrm{B}$ and $\mathrm{T}$ cells, which was similar to the mantle zone of the reactive lymphoid follicles $(\mathrm{p}<0.036)$. EBV infection was positive in three cases of CD; one case of HVCD (case 6) and two cases of PCCD (case 15 and 17). One case of plasmablastic lymphoma was co-expressed with HHV8 and EBV infection (case 17).

\section{Discussion}

CD is classified into two histologic subtypes; the HV and PC variants. The correlation between histological types and clinical setting is well established. Of the localized form of $\mathrm{CD}$, the HV type is found in $90 \%$ of cases and the PC type in $10 \%$ of cases, whereas of the MCD, the PC type is found in $83 \%$ and the HV type in $17 \%$ of cases in our study.

By immunohistochemisty, we found the distribution and expression of FDCs in lymphoid follicles from patients of CD. FDCs are a unique type of cells localized within lymphoid follicles. In normal immunity, FDCs play an important role in presenting antigen to $\mathrm{B}$ cells and regulating co-stimulatory interactions within the germinal centers. Most experimental data support the derivation of FDCs from local populations of stroma. A number of monoclonal antibodies that recognize human FDCs have been identified. Because a single marker was not enough to recognize the specific or related cells 
especially in paraffin embedded tissue section and the phenotypic alteration of human FDC determining their developmental stage and functional phase has been reported, two conventional antibodies, CD21 and CD35 and one new novel antibody EGFR were chosen for this study. In the present study, we found different expression of follicular dendritic network as determined by CD21, in the HVCD and PCCD which has been previously described by Nguyen et al (6). They reported an expanded, disrupted, follicular dendritic cell network in 10 cases and multiple tight collections of FDC in 16 out of $27 \mathrm{HVCD}$. In contrast, plasma cell variant was similar to those seen in normal or reactive germinal centers. However, our cases (Table III) showed an expanded or abnormal clustering pattern of FDC in all HVCD patients and 2 cases (33\%) of PCCD. Interestingly, two PCCD cases (cases 17 and 13) correlated with the histologic findings of mantle cell proliferation and regressed or abnormal germinal centers and therefore, could be classified as mixed variant rather than plasma cell variant of $\mathrm{CD}$. Character-istically, mantle zone lymphocytes of HVCD were positive for FDC markers, resulting in an expanded FDC mesh-work. The expanded FDC meshwork has been reported in some malignant lymphomas including mantle cell lymphoma, low grade MALT lymphoma, low grade follicular lymphoma, and angio-immunoblastic T cell lymphoma $(11,12)$. However, an abnormal FDC staining pattern with extrafollicular expansion, as presented herein, was well correlated with the morphological findings of markedly regressed or dysplastic follicles and thick mantle cell proliferation. We also found immunophenotypic difference of the mantle zone lymphocytes in HVCD and PCCD. The mantle zone lymphocytes of HVCD were exclusively B cells that stained positively for $\mathrm{Bcl} 2$, CD20, and PAX5, whereas those of PCCD contained B and $\mathrm{T}$ cells similar to the mantle zone of the reactive lymphoid follicles. In PCCD, presence of active germinal center with thin mantle cell layer and persistent B cell expansion suggest that these lymph nodes may respond to the factors driven either by immunological stimulus or by other factors such as HHV8. In contrast, less number of CD3 positive T cells and thick mantle cell proliferation with regressed germinal centers observed in HVCD, suggest that the lymph node may no longer be responding to the lymph-derived exogenous cytokine signals.

Epidermal growth factor receptor (EGFR) is a receptor tyrosine kinase frequently over-expressed in human cancers leading to a dysregulated proliferative or differentiation signal. Sun et al reported immunohistochemically up-regulation of EGFR in the FDC of CD both HV and PC types but not in the FDC of reactive germinal centers or in the FDC networks associated with several lymphoma types (10). Here, we also noted strong EGFR staining in FDC of lymphoid follicles in all HVCD and 2 cases of PCCD but it was not statistically significant. The EGFR expression distinguishes the longlived or immunophenotypically stable FDC in HVCD from the transient FDC that develop during the course of the immune response.

In normal lymphoid follicle seen in PCCD, EGFR expression was weakly positive and was restricted to germinal centers. The FDC in different stages and areas of the developing germinal centers showed a sequential pattern of FDC antigen. For example, the monoclonal antibody CD35 and CD21, one of mature or activated FDC markers precedes CD23 or additional molecules such as CD55, CD106 and S100a. Strong expression of CD35, CD21 and EGFR suggest a participation of full mature differentiated FDCs in HVCD. Currently a number of antibodies and inhibitors targeting EGFR are widely used as treatments for epithelial malignancies. Demonstration of EGFR in both CD subtypes can be used as a target for adjunctive agents in MCD or in cases of surgically unresectable CD.

With regard to the etiology and complications for CD, there have been a number of interesting observations in our cases that deserve further investigation. First, as illustrated by case 11 , follicular dendritic cell hyperplasia, dysplasia, and sarcoma are associated with HVCD similar to the previous reports $(13,14)$. Our cases showed both features of HVCD and a spindle cell mesenchymal tumor, which was diffusely stained with all 3 FDC markers used here and a low index of Ki-67.

Second, three of 17 CDs exhibited a few positive EBER by in situ hybridization, whereas one case of PCCD complicated by lymphoma was strongly positive for EBER and HHV8 LANA by immunohistochemistry in nuclei of plasmablastic lymphoma cells. By using PCR technique, detection of HHV8 was found in $40 \%$ of HIV negative and all cases of HIV-positive MCD (15). Immunohistochemical studies demonstrated that HHV8 is found in the plasmablasts within MCD $(16,17)$ and in malignant cells of plasmablastic lymphoma similar to our case 17. All patients with MCD in this study were HIV-negative. One case of MCD, illustrated by case 12 , developed a cutaneous Kaposi's sarcoma 29 months later. This is a well known and frequent association between Kaposi's sarcoma and MCD.

Finally, we have histological variants of HVCD. In cases 4 and 5, germinal centers of lymphoid follicles were entirely regressed and the follicle consisted only of great numbers of small mantle zone lymphocytes, resembling mantle zone lymphoma. Cases like these have been referred to as the lymphoid variants of HV (18). In contrast, a single enlarged follicle with multiple fragmented germinal centers has been described (18). In our case 6, the nodal architecture was obliterated with extensive proliferation of blood vessels and a mixture of other inflammatory cells mimicking an inflammatory pseudotumor. Of interest also is the fact that CD with IPT-like pattern showed a few EBER-positive signals but was negative for HHV8.

Although a diagnosis of fully developed HVCD is straightforward, we found that strong expression of FDC markers (CD21 and CD35) and EGFR with abnormal pattern were more clearly observed in HVCD compared to the PCCD. We also observed different immunophenotypes of mantle zone lymphocytes in lymphoid follicles in the two variants of CD. These differences, as presented herein, provide significant information in the differential diagnosis of the two histopathological variants of $\mathrm{CD}$.

\section{Acknowlegements}

This work was supported in part by the Kyung Hee University Research Fund in 200-8 (KHU-20080612). 


\section{References}

1. Keller AR, Hochholzer L and Castleman B: Hyaline-vascular and plasmacell types of giant lymph node hyperplasia of the mediastinum and other locations. Cancer 29: 670-683, 1972.

2. De Rosa G, Barra E, Guarino M and Gentile R: Multicentric Castleman's disease in association with Kaposi's sarcoma. Appl Pathol 7: 105-110, 1989.

3. Oksenhendler E, Duarte M, Soulier J, et al: Multicentric Castleman's disease in HIV infection: a clinical and pathological study of 20 patients. AIDS 10: 61-67, 1996.

4. Hsu SM, Waldron JA, Xie SS and Barlogie B: Expression of interleukin-6 in Castleman's disease. Hum Pathol 24: 833-839, 1993.

5. Chen WC, Jones D, Ho CL, Cheng CN, Tseng JY, Tsai HP and Chang KC: Cytogenetic anomalies in hyaline vascular Castleman disease: report of two cases with reappraisal of histogenesis. Cancer Genet Cytogenet 164: 110-117, 2006.

6. Nguyen DT, Diamond LW, Hansmann ML, Alavaikko MJ, Schroder H, Fellbaum C and Fischer R: Castleman's disease. Differences in follicular dendritic network in the hyaline vascular and plasma cell variants. Histopathology 24: 437-443, 1994.

7. Kim JE, Kim CJ, Park IA, et al: Clinicopathologic study of Castleman's disease in Korea. J Korean Med Sci 15: 393-398, 2000.

8. Pauwels P, Dal Cin P, Vlasveld LT, Aleva RM, van Erp WF and Jones D: A chromosomal abnormality in hyaline vascular Castleman's disease: evidence for clonal proliferation of dysplastic stromal cells. Am J Surg Pathol 24: 882-888, 2000.

9. Amin HM, Medeiros LJ, Manning JT and Jones D: Dissolution of the lymphoid follicle is a feature of the $\mathrm{HHV}^{+}$variant of plasma cell Castleman's disease. Am J Surg Pathol 27: 91-100, 2003.
10. Sun X, Chang K, Abruzzo LV, Lai R, Younes A and Jones D Epidermal growth factor receptor expression in follicular dendritic cells: a shared feature of follicular dendritic cell sarcoma and Castleman's disease. Hum Pathol 34: 835-840, 2003.

11. Bu X, Zheng Z, Wang C and Yu Y: Significance of C4d deposition in the follicular lymphoma and MALT lymphoma and their relationship with follicular dendritic cells. Pathol Res Pract 203: 163-167, 2007.

12. Jones D, Jorgensen JL, Shahsafaei A and Dorfman DM: Characteristic proliferations of reticular and dendritic cells in angioimmunoblastic lymphoma. Am J Surg Pathol 22: 956-964, 1998

13. Chan JK, Tsang WY and Ng CS: Follicular dendritic cell tumor and vascular neoplasm complicating hyaline-vascular Castleman's disease. Am J Surg Pathol 18: 517-525, 1994.

14. Lin O and Frizzera G: Angiomyoid and follicular dendritic cell proliferative lesions in Castleman's disease of hyaline-vascular type: a study of 10 cases. Am J Surg Pathol 21: 1295-1306, 1997.

15. Soulier J, Grollet L, Oksenhendler E, et al: Kaposi's sarcomaassociated herpesvirus-like DNA sequences in multicentric Castleman's disease. Blood 86: 1276-1280, 1995.

16. Du MQ, Liu H, Diss TC, et al: Kaposi sarcoma-associated herpes virus infects monotypic (IgM lambda) but polyclonal naive $\mathrm{B}$ cells in Castleman disease and associated lymphoproliferative disorders. Blood 97: 2130-2136, 2001

17. Oksenhendler E, Boulanger E, Galicier L, et al: High incidence of Kaposi sarcoma-associated herpesvirus-related non-Hodgkin lymphoma in patients with HIV infection and multicentric Castleman disease. Blood 99: 2331-2336, 2002.

18. Vasef M, Katzin WE, Mendelsohn G and Reydman M: Report of a case of localized Castleman's disease with progression to malignant lymphoma. Am J Clin Pathol 98: 633-636, 1992. 